\section{Down's syndrome with diabetes mellitus and hypothyroidism}

Sir,

The coexistence of diabetes mellitus in childhood and other endocrinopathies (especially thyroid ones) in the same patient or in other family members is well recognized.

Belief in the coexistence of Down's syndrome and other endocrinopathies moved previous generations of physicians to prescribe for mongolism oral 'polyglandular' preparations of which the only effective component was dry thyroid extract.

The coexistence of Down's syndrome, diabetes mellitus, and hypothyroidism is certainly rare enough to merit publication (Shaheed and Rosenbloom, 1973; Parkin, 1974). The coexistence of Down's syndrome and diabetes mellitus may be commoner (Farquhar, 1962, 1969) and might provide a further clue about the nature of an inherited factor in childhood diabetes. My experience of finding more than 1 Down's syndrome in every 100 diabetic children (i.e. at least 5 times what might be expected) may have been fortuitous, e.g. elderly mothers especially if potentially diabetic. The large number of children being registered nation-wide in the joint study by the British Diabetic and British Paediatric Associations should provide conclusive evidence one way or the other, but only if children with Down's syndrome have their urine tested when ill.

J. W. FARQUHAR Department of Child Life and Health, University of Edinburgh.

\section{REFERENCES}

Farquhar, J. W. (1962). Diabetic children in Scotland and the need for care. Scottish Medical fournal, 7, 119.

Farquhar, J. W. (1969). Early-onset diabetes in the general and the Down's syndrome population. Lancet, 2, 323.

Parkin, J. M. (1974). Down's syndrome, hypothyroidism, and diabetes mellitus. (Letter.) British Medical fournal, 2, 384.

Shaheed, W. A., and Rosenbloom, L. (1973). Down's syndrome with diabetes mellitus and hypothroidism. Archives of Disease in Childhood, 48, 917. 